\title{
A FRAMEWORK FOR CLOUD-BASED VIRTUAL AND AUGMENTED REALITY USING REAL-TIME INFORMATION FOR CONSTRUCTION PROGRESS MONITORING
}

\author{
Ranjith K. Soman ${ }^{1}$ and Jennifer K. Whyte ${ }^{2}$
}

\begin{abstract}
Researchers are developing techniques to use augmented reality for construction progress monitoring, but these are not widely diffused. A barrier to wider use is that BIM software is often not updated in real-time between the construction office and the construction site. This paper proposes an integrated cloudbased framework to enable construction progress monitoring by creating an automated real-time bidirectional flow of information between the construction site and planning office. This seeks to take advantage of the new opportunities arising because of the consumer VR/AR devices that have come to market in the last year, and the potential for engineers and site personnel to take ownership of these low-cost devices and use them in their role. It contributes to the trajectory of research on virtual and augmented reality in construction by articulating a novel approach to construction progress monitoring through passive data acquisition, cloud-based processing and use of consumer VR/AR devices. The paper concludes by articulating next steps to develop prototypes and work with industry partners to enable them to engage in innovation.
\end{abstract}

Keywords: Construction, augmented reality, virtual reality, cloud computing, automatic data collection

\section{INTRODUCTION}

New forms of project delivery are emerging that enable more rapid and agile forms of organizing (Levitt 2011). These use a digital infrastructure of computers, mobile devices, sensors, broadband network connections, and application platforms (Whyte \& Levitt 2011), which, in the construction phase, have the potential to permeate and transform the activities and relationships across the construction office and site. Although researchers are developing techniques to use augmented reality for construction progress monitoring; on most construction sites, current practices rely on relatively manual, time consuming inspections to assess progress and these investigations are prone to error (Golparvar-Fard et al. 2009). Where BIM software is implemented, it is often not updated in real-time between the construction office and the construction site. Thus there is not the intensification of innovation in this context that would be expected to result from digitization and use of 3D software (Dodgson et al. 2002; Boland et al. 2007).

Engineers at the construction site find it difficult to navigate through a complex BIM model and understand relevant attributes stored in the model (Kopsida et al. 2015). Because

1 Doctoral research scholar, Centre for Systems Engineering and Innovation, Department of Civil and Environmental Engineering, Imperial College London, UK, ranjithks17@imperial.ac.uk

2 Laing O'Rourke/RAEng Chair in Systems Integration, Professor, Department of Civil and Environmental Engineering, Imperial College London, UK, j.whyte@imperial.ac.uk 
BIM models are stored on servers or standalone computers they are often not updated synchronously at the site. In other words, there is considerable delay in passing the information from the planning office to the office at the construction site. This delay is critical in certain projects such as fast tracked projects where the design is made concurrent to the construction. Slower updating in such project results in project delay or rework. Hence it is understood that there should be real time information flow from the construction site to the planning office.

This paper proposes an integrated cloud-based framework for interactive visualisation and automated data collection enabling bi-directional flow between planning office and office at the construction site. This seeks to take advantage of the new opportunities arising as a result of the consumer VR/AR devices that have come to market in the last year, and the potential for engineers and site personnel to take ownership of these lowcost devices and use them in their role. It contributes to the trajectory of research on virtual and augmented reality in construction by articulating low-cost approaches to data acquisition, processing, and VR/AR to reduce the need for high computing devices. The paper is divided into four sections. Section 2 briefly describes the background and related work done in this area. Section 3 explains the proposed framework in detail. Over the next few months, we plan to develop the first prototype. Section 4 concludes by describing our contribution of a novel approach to construction progress monitoring through passive data acquisition, cloud-based processing and use of consumer VR/AR devices; and articulating next steps to develop prototypes and work with industry partners to enable them to engage in innovation.

\section{RELATED WORK}

This section briefs on the works related to visualization, cloud computing and data acquisition, which are three areas of prime focus in this research. There is a long tradition of considering virtual and augmented reality applications in construction (Bouchlaghem et al. 2005; Whyte 2003), with early applications using high-end computing; followed by applications on desktop and laptop computers. There are new opportunities to use smart phones along with cloud-based solutions (Kodeboyina and Varghese 2016). The immersive visualization enhances understanding of complex construction systems and facilitates the evaluation of different construction scenarios with limited expense and effort ( $\mathrm{Li}$ et al. 2003). Also, it increases synchronous collaboration between different parties involved in planning and design (Gu et al. 2011). The use of virtual reality during the design phase has proved to lead to specific design changes that enhance worker safety during construction (Sacks et al. 2015). The practitioners and researchers in the construction domain have realized the importance of visualization and have been keen to experiment with augmented reality for immersive visualization. Some of the works in the area include construction defect management (Vineet R. Kamat \& Sherif El-Tawil 2007), uncertainty aware excavation (Behzadan et al. 2015), dynamic visualization using GPS (Nigel 2013) and related work on augmented tele-operation and collaborative planning (Wang, Love, et al. 2014) and on drawing augmentation(Fiorentino et al. 2009). Whyte and Broyd (2015) have suggested the augmented reality in the construction domain be simple to use and integrated with the personal and protective equipment such that the users will have hands free access to rich information. There is significant commercial use of augmented reality for infrastructure operations which is evident in Bentley's research on panorama-based augmented reality (Côté et al. 2013). 
Cloud-based computing is another area which has empowered real-time collaboration and enabled project teams with the ability to extend BIM from design to construction (Porwal and Hewage 2013). Recently, BIM based services have enabled cloud computing for real-time collaboration. Considerable research works are done in this area basing BIM on a cloud. Chuang et al. (2011) used SaaS and cloud computing for developing a system for BIM visualization and manipulation through the web without the limitations of time or distance using Reality Server and MS SQL database. Jiao et al. (2013) have designed and implemented project data as a service cloud application model which solves the big-data life cycle management problem in the AEC/FM sector by correlating project engineering data and project management data through a seamless BIM and business social networking services federation. Chen et al. (2016) presents a cloud-based system based on Big table and MapReduce as the data storage and processing tools for providing a web-based service application for viewing, storing, and analysing massive building information models.

To enable effective visualisation, it is necessary to have real-time data. Advanced automated data collection technologies are being used today for real-time construction progress tracking. Geospatial tools such as RFID and GPS enable site managers to visualize on-site construction objects. Researchers have extensively studied these technologies for use in construction planning and automated data acquisition (Omar and Nehdi 2016; Song et al. 2006; Wang, Truijens et al. 2014; Kang and Hong 2015). However, this system becomes uneconomical when there is need to attach a GPS receiver to each site object (Khoury et al. 2015). Laser scanning is another method for acquiring site data. The acquired data from a laser scanner is a point cloud within a 3D coordinate system. Although laser scanners offer high accuracy, it needs trained users for the operation and has high maintenance costs. (Kiziltas et al. 2008). An alternative to laser scanning to capture as-built data is to use photogrammetry. Image based systems are relatively cheap and easier to use. Bohn \& Teizer (2010) have explored the benefits and challenges of progress monitoring using high resolution cameras. Continuous advancements on cameras and performance processing units enhance the accuracy of the obtained data, reduce the time of processing and increase the potential of using visual data for as-built data acquisition purposes. However, it is difficult to capture all the activities in construction site using imaging systems due to the dynamic nature of a construction site. It can be observed that there are numerous technologies capable of performing automated data collection leading to progress and productivity measurement.

\section{PROPOSED FRAMEWORK}

The study proposes a framework which integrates the information flow from the construction site to the office and vice versa. The key element of this framework is a cloudbased BIM information system where the information exchange takes place. It uses the acquired data and set thresholds (as designed thresholds) to automate decision making. Low impact decisions are made automatically where as high impact decisions may require human interventions. Schematic of the proposed framework is as shown in Error! Reference source not found..

At the construction office, different engineering teams would create a BIM model of the project, visualize it using Virtual Reality(VR) headsets and discuss the model between themselves for collaborative design. VR enabled visualisation will make 4D modelling efficient through effective visualization of interdependencies and interactions which may happen in the construction phase. The final model is then uploaded to BIM server. 
A Framework for Cloud-Based Virtual and Augmented Reality using Real-time Information for Construction Applications

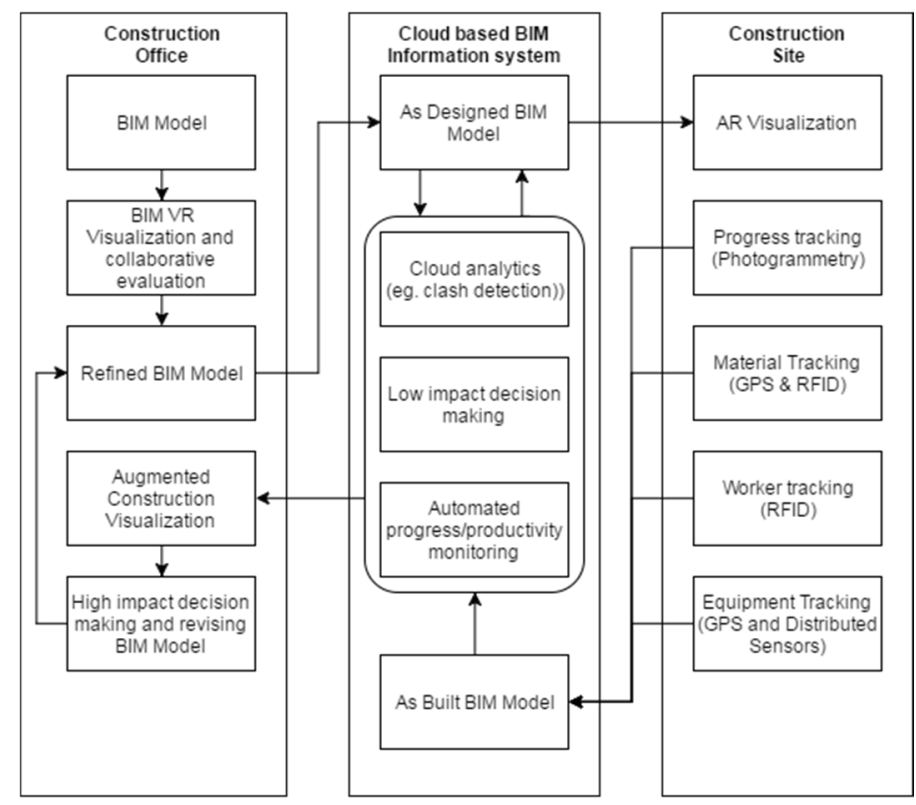

Figure 1: Framework for real-time information flow between construction office and site

At the construction site, supervisors and engineers use smartphones for visualizing the building elements by downloading the model from the BIM information system. The visualization can be made effective by using an Augmented Reality headset/AR-enabled smart mobile device. Overlaying the as-designed model of that stage onto the physical construction site would enable engineers and supervisors at the construction site to make a better judgement. During the visualization, same smartphone/tablet scans the 3D space and creates a 3D mesh of the construction site which can be then converted to an as-built model in the cloud information system. In addition, the data stream from sensors (such as RFID and GPS in the materials, equipment, and helmets of workers) can be used to update the use of materials and machine. This leads to a passive automated data collections system where in the data is crowd sourced from different sensors to a central server to aid subsequent decision making. The as-built model used to track the progress and the productivity of the project by overlaying the as-built model with the as-designed model. The as-built model can also be used to visualize the construction site virtually at the construction office using a VR headset. Modifications, as well as high impact decisions, can be made on the same if necessary, which will be updated to the as-designed model.

\subsection{Data Acquisition Devices}

The framework proposes that multiple data acquisition technologies to be used such that limitations of one technology are addressed by another technology. Advantages and disadvantages of the different technologies are summarised in Table 1. The proposed framework uses three different technologies(RFID, GPS, and Computer vision) for data acquisition. Although being the best imaging device for point cloud generation, LIDAR is not included in the current framework due to its high cost and the sheer size of the dataset. Instead, the proposal is to use a combination of stereo and IR cameras for 'continuous scanning' which will involve accurate 3D reconstruction leading to progress estimation. Four different areas have been given importance for the construction progress and productivity monitoring. The areas are as follows: 
1. Material tracking: It is done to ensure that usage and movement of the material used for construction is documented. Materials are tagged and monitored right from the factory all the way to its usage at the construction site. This allows detailed documentation of the material movement and prevents wastage and loss.

2. Worker tracking: Worker tracking is enabled through tags. Every time a worker enters the construction site, the person should go through a gate which scans the tag and enters the data into the database. Hence, the precise location of each worker and the duty times are recorded automatically. In addition, all the safety gears of the worker can be tagged. A worker can enter the construction only if all the safety gears are with him. This not only increases the safety but also the (Kodeboyina \& Varghese 2016)productivity due to enhanced safety.

3. Equipment tracking: Equipment tracking is necessary to monitor the usage and idle times of the equipment. These data will be relevant for optimising the deployment of resources on to the construction site. The data from this exercise can be used for the better planning and execution of future projects too.

4. Construction monitoring: This area of framework tracks the progress of the construction. It is critical for accurate planning and supply chain management. and provides a base for different productivity calculations and benchmarking such as earned value analysis.

The data acquisition for the above areas is carried out using the following data acquisition technologies as stated in Table 1.

\subsection{Devices for Augmented Reality}

Google daydream is a virtual reality (VR) and augmented reality (AR) platform developed by Google for use with a head mount for a mobile phone. Recently, there is a surge in the development and support using this platform and hence this platform would be ideal for the current framework due to the lesser cost and added advantage and customization. We draw this conclusion from the analysis of the significant cost factor which limits the application of VR/AR technologies being used in construction applications. Commercially available VR /AR devices, range from Microsoft HoloLens (\$3000); HTC Vive (\$799); Oculus Rift (\$600); Samsung Gear VR (\$100); Google Daydream VR (\$79); Google Cardboard (\$20)(Kodeboyina \& Varghese 2016).

The cost of an AR device is the combined cost of application building and the cost of hardware. The cost of application depends significantly on the development of backend software. The advent of open source reconfigurable hardware platforms makes it possible for a creative backend to be hosted on a relatively cheaper hardware, thereby decreasing the cost of the AR device. Google Cardboard and Daydream VR are two platforms which use smartphones as the processing and visualisation device to enable Augmented/Virtual reality. As the smartphone has become inescapable in the current era, this framework can make use of the extensible capabilities of this platform in providing AR experience for construction applications. 
A Framework for Cloud-Based Virtual and Augmented Reality using Real-time Information for Construction Applications

Table 1: Strengths and weaknesses of technologies for data acquisition

\begin{tabular}{|c|c|}
\hline $\begin{array}{c}\text { Data } \\
\text { acquisition } \\
\text { technology }\end{array}$ & Strengths and weaknesses \\
\hline \multirow[t]{2}{*}{$\begin{array}{l}\text { Geospatial } \\
\text { tools }\end{array}$} & $\begin{array}{l}\text { RFID: The contactless nature is an advantage. RFID tags can be automatically } \\
\text { scanned (for worker tracking) or read using a hand-held reader (predominantly } \\
\text { used for material tracking). RFID tags can be passive, active or hybrid based on the } \\
\text { requirements. Active tags have to powered externally and have a higher range } \\
\text { (500m range). Passive tags need not be powered thus resulting in shorter ranges } \\
(15 \mathrm{~m}) \text {. A hybrid tag behaves as an active tag when a signal is triggered and } \\
\text { otherwise remains passive. High value items can be associated with an active tag } \\
\text { and other items associated with a passive tag. A hybrid tag with an inbuilt battery } \\
\text { can be used as a worker tag, switching on when the worker enters the site. }\end{array}$ \\
\hline & $\begin{array}{l}\text { GPS: Commercially available GPS devices enable the continuous data logging of } \\
\text { equipment location in construction. GPS is independent and does not require other } \\
\text { sensing infrastructure to be present on a project (Pradhananga \& Teizer 2013). } \\
\text { Deploying GPS sensors on equipment will help the manager benchmark its } \\
\text { performance and productivity which will help in later planning. Also, non- } \\
\text { performing assets can be easily identified and corrective actions could be taken. }\end{array}$ \\
\hline \multirow[t]{2}{*}{$\begin{array}{l}\text { Imaging } \\
\text { devices }\end{array}$} & $\begin{array}{l}\text { Digital cameras: These are both the normal 'point and shoot' cameras with high } \\
\text { resolution. A 3D point cloud can be generated from these cameras using two } \\
\text { methods. First, photogrammetry is a robust method to create a 3D point cloud from } \\
\text { digital images. However, the time taken to generate the 3D point cloud and its } \\
\text { resource intensive nature limit its application in the current framework. Second, } \\
\text { videogrammetry technology extracts the features from video frames. As the video } \\
\text { frames are sequential and use progressive reconstruction, videogrammetry } \\
\text { enhances civil infrastructure reconstruction more efficiently than photogrammetry. }\end{array}$ \\
\hline & $\begin{array}{l}\text { Range cameras: These cameras give a depth value for each pixel in addition to the } \\
\text { RGB values. They offer inexpensive and accurate means for digitizing the shape of } \\
\text { the construction site. Two common range camera technologies are infrared } \\
\text { cameras and stereovision cameras. Stereovision cameras have two sensors } \\
\text { separated at a distance. Depth is computed from the sensed images using } \\
\text { trigonometric computations. Stereovision cameras have range up to } 20 \mathrm{~m} \text {. Infrared } \\
\text { cameras use IR sensor to compute the distance between the object and camera. This } \\
\text { has a range of } 1.5 \text { m only. However, the processing time to create a 3D point cloud } \\
\text { for an IR camera is much lesser to the resource intensive stereo camera. }\end{array}$ \\
\hline
\end{tabular}

\section{CONCLUSION}

The paper proposes an integrated cloud-based framework to ensure real time bidirectional information flow between planning and construction site for construction progress monitoring. It contributes to the trajectory of research on virtual and augmented reality in construction by articulating a novel approach to construction progress monitoring through passive data acquisition, cloud-based processing and use of consumer VR/AR devices. A single data acquisition technology cannot be used to measure the progress of a complex construction project. Therefore, an integrated framework combining different technologies such as virtual and augmented reality, cloud computing, 
real-time building information modelling, RFID, GPS and computer vision is proposed which compensates the limitations of using a single technology. The framework ensures automated data collection and fast processing of raw data into meaningful BIM representation with the help of a cloud server. The proposed framework enables visualisation at the construction site without the need of high-end computing devices, thereby, extending the reach of BIM application all the way to the construction front.

The next steps are to develop prototypes and work with industry partners to enable them to engage in innovation. The process is in place to create an information flow from the construction site to construction office using wearable technologies. This future work includes testing and developing a prototype (hardware + software) for implementing the proposed framework and testing it on a live construction site. The influence of the bidirectional information flow on the productivity will be studied in detail and interaction between the site and office obtained from the recorded logs is an interesting area to be researched upon to understand site - office interactions for academicians.

\section{REFERENCES}

Behzadan, A.H., Dong, S. and Kamat, V.R. (2015). Augmented reality visualization: A review of civil infrastructure system applications. Advanced Engineering Informatics, 29(2), pp.252-267.

Bohn, J.S. and Teizer, J. (2010). Benefits and Barriers of Construction Project Monitoring Using High-Resolution Automated Cameras. Journal of Construction Engineering and Management, 136(6), pp.632-640.

Boland, R.J., Lyytinen, K. and Yoo, Y. (2007). Wakes of Innovation in Project Networks: The Case of Digital 3-D Representations in Architecture, Engineering, and Construction. Organization Science, 18(4), pp.631-647.

Bouchlaghem, D. et al. (2005). Visualisation in architecture, engineering and construction (AEC). Automation in Construction, 14(3), pp.287-295.

Chen, H., Chang, K. and Lin, T. (2016). A cloud-based system framework for performing online viewing, storage, and analysis on big data of massive BIMs. Automation in Construction, 71, pp.34-48.

Chuang, T.-H. et al. (2011). Applying Cloud Computing Technology To Bim Visualization And Manipulation. ISARC Proceedings, 2011, pp.144-149.

Côté, S. et al. (2013). Live Mobile Panoramic High Accuracy Augmented Reality for Engineering and Construction. Proc. Int'l Conf. on Construction Applications of Virtual Reality (CONVR'13), (October), pp.30-31.

Dodgson, M., Gann, D.M. and Salter, A.J. (2002). The Intensification of Innovation. International Journal of Innovation Management, 6(1), pp.53-83.

Fiorentino, M., Monno, G. and Uva, A.E. (2009). Tangible digital master for product lifecycle management in augmented reality. International Journal on Interactive Design and Manufacturing (IIIDeM), 3(2), pp.121-129.

Golparvar-Fard, M., Peña-Mora, F. and Savarese, S. (2009). D4AR-a 4-dimensional augmented reality model for automating construction progress monitoring data collection, processing and communication. ITcon Vol. 14, pg. 129-153

Gu, N., Kim, M.J. and Maher, M. (2011). Technological advancements in synchronous collaboration: The effect of 3D virtual worlds and tangible user interfaces on architectural design. Automation in Construction, 20(3), pp.270-278. 
Jiao, Y. et al. (2013). A cloud approach to unified lifecycle data management in architecture, engineering, construction and facilities management: Integrating BIMs and SNS. Advanced Engineering Informatics, 27(2), pp.173-188.

Kang, T.W. and Hong, C.H. (2015). A study on software architecture for effective BIM/GIS-based facility management data integration. Automation in Construction, 54, pp.25-38.

Khoury, H. et al. (2015). Infrastructureless approach for ubiquitous user location tracking in construction environments. Automation in Construction, 56, pp.47-66.

Kiziltas et al. (2008). Technological Assessment and Process Implications of Field Data Capture Technologies for Construction and Facility / Infrastructure Management. Journal of information technology in construction, 13(April), pp.134-154.

Kodeboyina, S.M. and Varghese, K. (2016). Low Cost Augmented Reality Framework for Construction Applications. In Proceedings of 33rd ISARC.

Kopsida, M., Brilakis, I. and Vela, P. (2015). A Review of Automated Construction Progress and Inspection Methods. In Proceedings of the 32nd CIB W78 Conference on Construction IT. pp. 421-431.

Levitt, R. (2011). Towards project management 2.0. Engineering Project Organizational Journal, 1(3), pp.197-210.

Li, H. et al. (2003). Virtual experiment of innovative construction operations. Automation in Construction, 12(5), pp.561-575.

Nigel, M. (2013). Model Based System for Contextual on-Site Construction Planning in Augmented Reality. University of Wolverhampton.

Omar, T. and Nehdi, M.L. (2016). Data acquisition technologies for construction progress tracking. Automation in Construction, 70, pp.143-155.

Porwal, A. and Hewage, K.N. (2013). Building Information Modeling (BIM) partnering framework for public construction projects. Automation in Construction, 31, pp.204214.

Sacks, R. et al. (2015). Safety by design: dialogues between designers and builders using virtual reality. Construction Management and Economics, 33(1), pp.55-72.

Song, J. et al. (2006). Automating the task of tracking the delivery and receipt of fabricated pipe spools in industrial projects. Automation in Construction, 15(2), pp.166-177.

Vineet R. Kamat and Sherif El-Tawil (2007). Evaluation of Augmented Reality for Rapid Assessment of Earthquake-Induced Building Damage.

Wang, X. et al. (2014). Integrating Augmented Reality with Building Information Modeling: Onsite construction process controlling for liquefied natural gas industry. Automation in Construction, 40, pp.96-105.

Wang, X. et al. (2014). Mutual awareness in collaborative design: An Augmented Reality integrated telepresence system. Computers in Industry, 65(2), pp.314-324.

Whyte, J. (2003). Industrial applications of virtual reality in architecture and construction. Electronic Journal of Information Technology in Construction, 8(Special issue Virtual Reality Technology in Architecture and Construction), pp.43-50.

Whyte, J. and Broyd, T. (2015). Viewing Asset Information: Future Impact of Augmented Reality. Proc. of the 32nd CIB W78 Conference 2015,, pp.754-761.

Whyte, J. and Levitt, R. (2011). Information Management and the Management of Projects, Oxford University Press. 